\title{
Brain abscess due to Haemophilus aphrophilus: case report
}

\author{
J. YAMASHITA, F. J. BONE, AND EDWARD HITCHCOCK \\ From the Departments of Surgical Neurology and Microbiology, \\ Western General Hospital, Edinburgh
}

SUMMARY A temporal lobe abscess due to $H$. aphrophilus occurred in a child of 11 years, and was successfully treated by aspiration, chemotherapy, and excision of the abscess wall. The organism is an unusual cause of brain abscess and this is believed to be the first reported case in Britain.

Haemophilus aphrophilus is an infrequent cause of human infection. Since Khairat first described this organism as a cause of endocarditis in 1940 in London, 63 additional infections have been reported, mostly in the U.S.A. (Fager, 1961; King and Tatum, 1962; Keith and Lyon, 1963; Isom, Gordy, Selner, Brown, and Willis, 1964; Dung and Lin, 1966; Page and King, 1966; Speller, Prout, and Saunders, 1968; Batshon and Brosius, 1969; Farrand, Maccabe, and Jordan, 1969; Sutter and Finegold, 1970).

In 64 cases reported, endocarditis was the usual presentation (33 cases) although there were 12 cases with brain abscess. Mortality is high in endocarditis $(26.5 \%)$ and brain abscess $(50 \%)$ (Sutter and Finegold, 1970). Infections other than endocarditis and brain abscess, however, have an excellent prognosis. Since the original account only two cases of infection due to $H$. aphrophilus have been reported in Britain (Speller et al., 1968; Farrand et al., 1969), both of which presented as endocarditis.

Several of the reported infections involved the respiratory tract (Page and King, 1966) and a number of cases of endocarditis and of brain abscess had a history of respiratory infection, dental disease or surgery (Keith and Lyon, 1963; Page and King, 1966). One patient had a history of a human bite (Page and King, 1966). The source of the infection was not established but Sutter and Finegold (1970) postulated that $H$. aphrophilus is present as a normal commensal in the mouth and upper respiratory tract of humans, although there are no reports of isolation of $H$. aphrophilus from such sources. In several reported cases dogs were suggested as the source of infection and in two cases (Fager, 1961; Isom et al., 1964), H. aphrophilus was cultivated from the saliva of each patient's dog.

The rarity of such infection prompted us to report on the successful management of a case of brain abscess due to $H$. aphrophilus, this being the first recorded in Britain.

\section{CASE HISTORY}

An 11 year old girl was admitted under the care of one of the authors (E.H.) on 28 September 1971 in a state of coma. Two weeks earlier she had a sudden headache with vomiting and fever, associated with a purulent discharge from the right ear. On admission to a local hospital there were no localizing neurological signs. Her past medical history was unremarkable. Meningitis was suspected and although the cerebrospinal fluid (CSF) contained 4,000 polymorphonuclear cells per cu. $\mathrm{mm}$, no microorganisms were obtained on culture. She responded well to systemic ampicillin and within 10 days her CSF contained only 37 cells per cu. mm. Four days later she was removed from hospital against medical advice.

On the day of her readmission to hospital her mother was unable to rouse her. The child was found to respond only to painful stimuli, with her right pupil fixed and dilated. She was immediately transferred to this department where an immediate right temporal burr hole was made. An abscess cavity was encountered $3 \mathrm{~cm}$ from the cortical surface and $70 \mathrm{ml}$. of thick, green, purulent material was aspirated and sent for culture. A mixed solution of $1 \mathrm{ml}$. micropulverized barium sulphate and $2 \mathrm{ml}$. cloxacillin 
(20 mg) was instilled into the abscess cavity. A rubber drain was left in place for daily aspiration. An immediate check radiograph revealed the abscess cavity, $4 \times 6 \times 8 \mathrm{~cm}$, in the right temporal region. Treatment was begun with systemic ampicillin 500 mg q.i.d., streptomycin $750 \mathrm{mg}$ daily, sulphadimidine $1 \mathrm{~g}$ q.i.d., potassium chloride $600 \mathrm{mg}$ t.i.d., and dexamethasone on the reducing dose. A prophylactic anticonvulsant, phenytoin sodium $50 \mathrm{mg}$ t.i.d. was also prescribed.

The abscess cavity was aspirated daily and instilled with $20 \mathrm{mg}$ ampicillin. Repeated check radiographs showed gradual reduction in the size of the abscess and the drain was removed 6 days after the original aspiration.

Although she continued to improve, her response to treatment was not as rapid as anticipated. Slow improvement and the very large size of the abscess indicated that it should be excised. On 7 October a right temporal craniotomy was performed and the abscess capsule was encountered quite superficially. It was irregularly lobulated and approximately $4 \mathrm{~cm}$ in diameter. It was completely removed. The petrous bone appeared normal and there was no direct connection between it and the abscess. Histological sections revealed a typical abscess wall, but cultures were negative.

The patient was discharged four weeks after admission to the Neurosurgical Unit. On 13 January 1972 an extended cortical mastoidectomy was carried out. $H$. aphrophilus was not isolated.

BACTERIOLOGY Purulent material obtained at the original aspiration was cultured on blood agar and brain-heart infusion agar, both aerobically and anaerobically, on MacConkey agar aerobically, and on chocolate blood agar in an atmosphere of $10 \%$ carbon dioxide.

After overnight incubation, large numbers of an organism later identified as $\boldsymbol{H}$. aphrophilus were obtained together with small numbers of a $\beta$ haemolytic streptococcus. On primary isolation the streptococcus was sensitive to penicillin, ampicillin, tetracycline and chloramphenicol but resistant to streptomycin.

The other organism, a small Gram negative bacillus, failed to grow on MacConkey agar, but grew equally well in all atmospheres and on all the other culture media as a minute, slightly haemolytic translucent colony. On subculture it required $\mathrm{X}$ but not $\mathrm{V}$ factor. This dependence was reduced in an atmosphere of $10 \%$ carbon dioxide and abolished under anaerobic conditions. It was catalase negative and fermented glucose with gas formation, but did not attack lactose, sucrose, or mannitol. On primary isolation it showed some resistance to ampicillin and streptomycin but on subculture it was sensitive to both these and to penicillin G, chloramphenicol, tetracycline, erythromycin, and cephaloridine.

Cultures from this child's nose, throat, aural discharge, and abscess cavity failed to reveal any obvious pathogen.

There had been a history of intimate contact with as dog and therefore repeated cultures of this dog's saliva were prepared. No such organism was found.

\section{DISCUSSION}

The source of this unusual infection is not obvious. Haemophilus aphrophilus was so named $\overline{\frac{}{\omega}}$ because of its preference for an atmosphere of $\vec{\Phi}$ carbon dioxide, 'aphros' being the foaming of fermenting wine. Its predilection for brain involvement in vivo is reflected in the fact that the $\vec{\circ}$ organism grows exceptionally well on brain $\vec{\omega}$ infusion agar in a candle jar (Keith and Lyon, 1963). The factors responsible for the vigorous growth in the brain tissues are unknown.

Animal pets have been suggested as a source of infection. Dogs in particular have been shown to 0 harbour the causative organism in two case $\overline{0}$ although little is known of the commensal flor 응 of dogs' upper respiratory passages. Insufficierg is known of the normal habitat of this organisie to confirm the suggestions of normal huma $\varnothing$ upper respiratory tract carriage, and, although all the likely sources of this infection were r\&్ㅇㅇ. peatedly searched, no success was achieved. $\vec{\ominus}$

The pathogenesis, presentation, and course of $N$ brain abscess due to this organism do not appear to have any unusual features.

Antibiotic therapy is essential. Haemophilus species seem to respond best to ampicillin, chloramphenicol, tetracycline, and to the aminoglycoside antibiotics. Response is often variable to penicillin, cephaloridine, erythromycin, lincomycin, and sulphonamides. The results of Sutten and Finegold (1970) seem to suggest that $H$. aphrophilus falls into the same pattern. For uncomplicated infection due to $H$. aphrophilus the treatment of choice seems to be penicillin plus streptomycin (Dung and Lin, 1966). In this case the organism was sensitive to the chemotherapy chosen on clinical grounds, so no change seemed indicated.

The authors are grateful to Dr. J. G. Gould for helpful advice and criticism on the bacteriology and $\mathrm{Dr}$. 
K. McLay for cooperation with the investigation of the mastoid disease.

\section{REFERENCES}

Batshon, B. A., and Brosius, O. C. (1969). A case of cerebral abscess with Haemophilus aphrophilus cultured from spinal fluid. American Journal of Clinical Pathology, 52, 356-357.

Cowan, S. T., and Steel, K. J. (1965). Manual for the Identification of Medical Bacteria, p. 86. Cambridge University Press: London.

Dung, W. M. H., and Lin, T. K. (1966). Subacute bacterial endocarditis due to Hemophilus aphrophilus. American Heart Journal, 71, 251-253.

Fager, C. A. (1961). An unusual brain abscess: report of a case. Lahey Clinic Bulletin, 12, 108-112.

Farrand, R. J., Maccabe, A. F., and Jordan, O. W. (1969). Haemophilus aphrophilus endocarditis. Journal of Clinical Pathology, 22, 486-487.

Isom, J. B., Gordy, P. D., Selner, J. C., Brown, L. J., and
Willis, M. (1964). Brain abscess due to Haemophilus aphrophilus. New England Journal of Medicine, 271, 10591061.

Keith, T. A. III, and Lyon, S. A. (1963). Hemophilus aphrophilus endocarditis. American Journal of Medicine, 34, 535-540.

Khairat, O. (1940). Endocarditis due to a new species of Haemophilus. Journal of Pathology and Bacteriology, 50, 497-505.

King, E. O., and Tatum, H. W. (1962). Actinobacillus actincmycetemcomitans and Haemophilus aphrophilus. Journal of Infectious Diseases, 111, 85-94.

Page, M. I., and King, E. O. (1966). Infection due to Actinobacillus actinomycetemcomitans and Haemophilus aphrophilus. New England Journal of Medicine, 275, 181-188.

Speller, D. C. E., Prout, B. J., and Saunders, C. F. (1968). Subacute bacterial endocarditis caused by a microorganism resembling Haemophilus aphrophilus. Journal of Pathology and Bacteriology, 95, 191-198.

Sutter, V. L., and Finegold, S. M. (1970). Haemophilus aphrophilus infections: clinical and bacteriologic studies. Annals of the New York Academy of Science, 174, 468-487. 